\title{
Textured PDMS films applied to thin crystalline silicon solar cells
}

\author{
A. Rosell, I. Martín, M. Garín, G. López and R. Alcubilla
}

\begin{abstract}
Front surface texturization is a standard procedure used to improve optical properties of photovoltaic devices. In some particular cases, such as when dealing with ultrathin substrates, common texturization techniques can become unpractical or even unfeasible. Texturized polymer films applied on top of such devices may be used as an alternative. In this work, we report on the development of textured PDMS films to be placed on top of planar crystalline silicon solar cells based on thin substrates $(\leq 40$ $\mu \mathrm{m})$. The PDMS polymer is deposited onto a rough surface (conventional random pyramid textured silicon), cured and detached from it. By SEM images, we demonstrate that the dilution of PDMS into toluene helps in a better replica of the master surface. Next, we apply the optimized PDMS films on top of dummy samples based on 10, 20 and $40 \mu$ m-thick crystalline silicon (c-Si) substrates whose reflectance is significantly reduced after placing the PDMS films. Accurate optical simulations indicate that the optical improvement comes from three mechanisms: higher light transmission into the device, lower reflectance at the c-Si surface and better light trapping properties at the thin c-Si absorber. Experimental verification of the optical improvement with texturized PDMS films is reported based on $\mathbf{4 0}$ $\mu \mathrm{m}$ thick solar cell where a short-circuit current density gain of $\mathbf{1 . 7}$ $\mathbf{m A} / \mathbf{c m}^{2}$ is observed.
\end{abstract}

Index Terms - Thin crystalline silicon solar cells, surface texture

\section{INTRODUCTION}

$\mathrm{P}$ HOTOVOLTAIC devices suffer from reflection losses at the front surface due to the high refractive index contrast between the air and the absorber. One way to reduce these losses in a wide spectrum range is through the definition of some texture patterning with two main strategies. On the one hand, structures whose size is bigger than the incident wavelength can be defined in order to scatter the incoming light and increase the probability of the photon transmission through multiple reflections. Examples for this strategy are the random upright pyramids on monocrystalline silicon substrates [1-2], the isotextured surface found in multicrystalline silicon solar cells [3-4] or the texturized surfaces for amorphous silicon solar cells [5-6]. On the other hand, nanopatterning is used to define structures smaller than the incident wavelengths creating a gradual transition of refractive indexes such as the case of black silicon surfaces [7-8]. A combination of both strategies have been also explored with promising results [9].

Such patterning strategies may not be technologically feasible. This is the case for epitaxially growth III-V solar cells or for most of thin film technologies. In such cases, a texturized transparent film could be deposited on top of the device [1012]. These films are typically fabricated based on polydimethylsiloxane (PDMS) films that replicate a textured surface of a master [13-14].

Among all the devices where this approach can be useful, we are interested in c-Si solar cells fabricated on thin substrates $(\leq$ $40 \mu \mathrm{m}$ ). Most common texturization methods, such as random pyramids formation by alkali etchants, typically reduce 5-10 $\mu \mathrm{m}$ in thickness on each surface. Taking advantage of this, 30$40 \mu \mathrm{m}$ thick texturized solar cells obtained by thinning down thicker substrates can be found in the literature [15]. However, the consumption of large amounts of silicon to define the texturized surface jeopardizes the feasibility of this technique to obtain thinner substrates and reduces the interest of using thin c-Si substrates as a cost-effective approach. Possible alternatives like plasma etching [16] or the already mentioned black silicon [7-8] are more suitable techniques, but difficult to apply onto stand-alone thin c-Si substrates due to their fragility. Moreover, the introduction of texturized PDMS films avoid the possible increase in surface recombination due to the texturized c-Si surface.

In this work, we report on the development of textured PDMS films and their application to solar cell structures on thin c-Si substrates glued onto glass carriers to minimize their risk of breakage. In particular, we firstly focus on the manufacturing process of the PDMS films that leads to a better replica of the master. Next, we apply these films onto experimental samples on thin c-Si substrates to characterize them. Using optical simulations, we analyse the potential improvement in optical response focusing on light trapping properties in the thin c-Si absorbers due to the presence of texturized PDMS films. Finally, experimental verification of the optical improvement is reported.
Manuscript received April $10^{\text {th }}, 2019$. This work was funded by MINECO from Spanish government under projects TEC2017-82305-R, ENE201678933-C4-1-R, ENE2017-87671-C3-2-R. The work was also supported in part by project REFER COMRDI15-1-0036 funded by ACCIÓ and the European Regional Development Fund (FEDER).

Arnau Rosell, Isidro Martín, Gema López and Ramon Alcubilla are with the Departament d'Enginyeria Electrònica, Universitat Politècnica de Catalunya,
08034 Barcelona, Spain. (e-mail: arnau.rosell.canet@gmail.com, isidro.martin@upc.edu, gema.lopez@upc.edu, chen.jin@upc.edu, ramon.alcubilla@upc.edu). Moises Garín was with Department of Micro and Nanosciences, Aalto University, Tietotie 3, Espoo 02150, Finland. He is now with Departament d'Enginyeria, Universitat de Vic - Universitat Central de Catalunya (UVIC-UCC), Campus Torre dels Frares, c/ de la Laura 13, 08500 Vic, Spain. (e-mail: moises.garin@uvic.cat). 


\section{EXPERIMENTAL}

We used PDMS elastomer 184 Sylgard from Dow Corning as polymer. It is supplied as a 2-part liquid component kit that must be mixed in a 10:1 mass ratio. Apart from these two basic components, we add toluene in three different PDMS:toluene volume proportions of 5:1, 10:1 and 15:1. After extracting the bubbles in vacuum, we deposit the mixture onto the master surface which was previously dipped into toluene to help in the subsequent detachment of the PDMS foils. In this work, we use a random-pyramid textured c-Si substrate with pyramids in the range of 2-5 $\mu \mathrm{m}$ tall in order to benefit from both lower front reflectance and better light trapping properties. Although the obtained mixture could be cured in short times by increasing the temperature, we decided to cure it at room temperature to get a flexible elastomer that could better replicate the master surface. After 48 hours of curing, the flexible film is detached obtaining a negative replica of the master surface. Typical thickness of the PDMS film is $\sim 160 \mu \mathrm{m}$.

\section{RESULTS AND DISCUSSION}

\section{A. Replica quality}

In figure 1, we show Scanning Electron Microscope (SEM) images of the textured PDMS surface for the three explored PDMS:toluene dilutions namely 5:1, 10:1 and 15:1. As it can be seen in the figures, the quality of the texture transfer is very dependent on the dilution used. Soft edges and defects (randomly distributed small pores) in the PDMS films can be seen for the 15:1 film over all the explored surface. These defects tend to vanish as the toluene content increases. As a consequence, 5:1 dilution sample is almost free of them suggesting that the highest toluene dilution explored in this work leads to better quality textured PDMS films. All images in figure 1 clearly show the formation of sharp deep valleys in the PDMS films which correspond to the pyramid apex of the master. The sharpness of this feature could be considered as a good indicator of the conformability of the PDMS film and, thus, the quality of the replicated surface. In the insets of figure 1, we show a detail of the pyramid apex which was revealed through Focused Ion Beam (FIB) etching for the three toluene dilutions. In these images, we can see that the 15:1 sample shows a round vertex while for the 5:1 sample much sharper feature is observed. Based on these results, we can conclude that the toluene dilution of the PDMS film helps in a more accurate replica of the master surface. For the rest of the results reported in this paper, PDMS foils were fabricated using 5:1 PDMS:toluene dilution which is the highest one explored in this work.

\section{B. Experimental verification of improvement of optical absorption for thin c-Si substrates}

Once we have developed a fabrication process that is able to replicate master surface, we apply these films to increase optical absorption of thin c-Si substrates. In particular, we use double side polished 40, 20 and $10 \mu \mathrm{m}$ thick FZ c-Si substrates provided by Virginia Semiconductor. Due to the fragility of these substrates, a mechanical carrier is needed for proper handling and processing, especially for the thinnest ones. Our idea to fabricate a solar cell onto them is to passivate the front
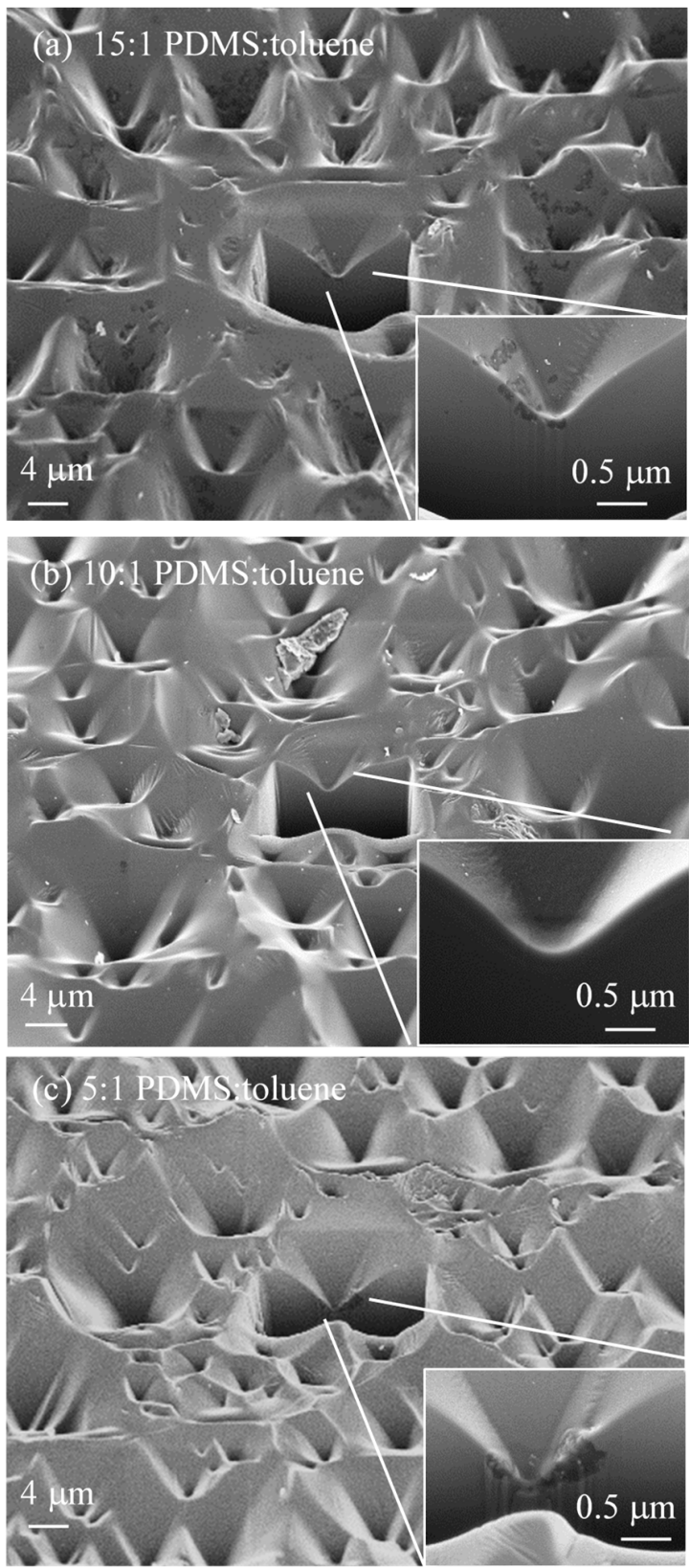

Fig. 1. SEM images of textured PDMS foils with PDMS:toluene dilutions of (a) $15: 1$, (b) $10: 1$ and (c) $5: 1$. In the insets a zoom of one pyramid vertex for every corresponding dilution is shown.

surface and glue them onto a highly transparent glass permitting access to the rear surface where electron and hole contacts can be defined in an Interdigitated Back-Contacted (IBC) structure [11][17]. In order to characterize the impact of the texturized PDMS films on such devices, we fabricate samples that mimic the optical configuration of the solar cell structure in a simplified way and whose cross-section can be seen in figure 2.(a). 
Taking advantage that Atomic Layer Deposition technique allows an easy growth on both sides of the sample, we have identical aluminum oxide $\left(\mathrm{Al}_{2} \mathrm{O}_{3}\right)$ layers on both sides of the wafer. At the front surface, this layer will be present in the final cell structure because it provides excellent surface passivation and improves optical response of the cell [18-19], while at the rear surface the $\mathrm{Al}_{2} \mathrm{O}_{3}$ layer is coated with an evaporated Aluminum film to create a back reflector. Finally, we use a transparent epoxy EpoTek 302-3M to glue the sample onto a $0.7 \mathrm{~mm}$ Schott Borofloat 33 glass. (a)

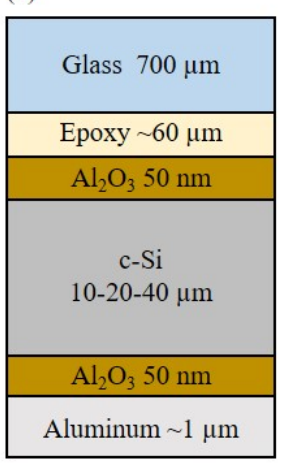

(b)

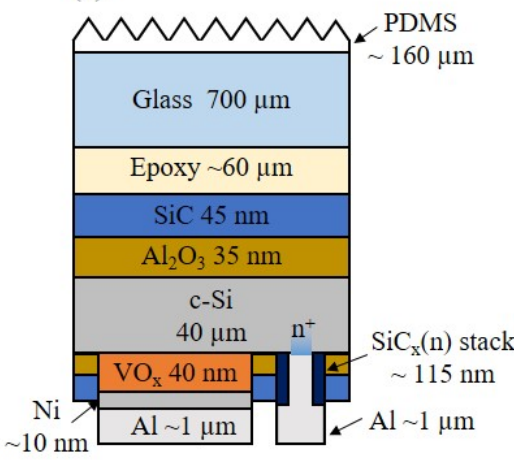

Fig. 2. (a) Cross-section of the samples fabricated to evaluate the optical improvement by introducing the PDMS film. Texturized PDMS films are placed on top of the glass. (b) Cross-section of the fabricated solar cells.

Figure 3 shows the reflectance $(R)$ measurements with and without the PDMS film for the three sample thicknesses. As it can be seen, similarly to other reported results [14] a strong reduction of the reflectance is measured in all cases when the texturized PDMS film is introduced indicating that more light is absorbed in the c-Si substrate. In order to quantify this improvement in c-Si optical absorption, we perform optical simulations using raytracing software GenPro4 [20]. We reproduce the sample structure while optical properties of the different films (refractive index, $n$, and extinction coefficient, k) were obtained through different ways. For the thin $\mathrm{Al}_{2} \mathrm{O}_{3}$ films, spectroscopic ellipsometry measurements were carried out while constants for Aluminum [21] and c-Si [22] were extracted from the literature. Extinction coefficients of the epoxy, the glass and the PDMS film were experimentally determined by measuring absorptance and applying the BeerLambert law [23]. Finally, refractive index of epoxy and PDMS were obtained from their datasheets while for the glass we used data reported in [24]. Regarding top surface geometry of the texturized PDMS, we defined inverted pyramids using the data given by the simulator manufacturer as typical random pyramid c-Si texturization which reproduces the master surface used.

With all this information, we carried out the simulations with only one free parameter: c-Si substrate thickness. The indicated thickness values are nominal values with tolerance of $\pm 2 \mu \mathrm{m}$ for 10 and $20 \mu \mathrm{m}$ thick substrates and $\pm 4 \mu \mathrm{m}$ for $40 \mu \mathrm{m}$ thick ones. The substrate thickness was adjusted in the simulations inside these intervals in order to get the best fit of the experimental data. The results can be seen in figure 3 where a good agreement is obtained between experimental and simulated data indicating that optical response of texturized PDMS films are accurately modeled.

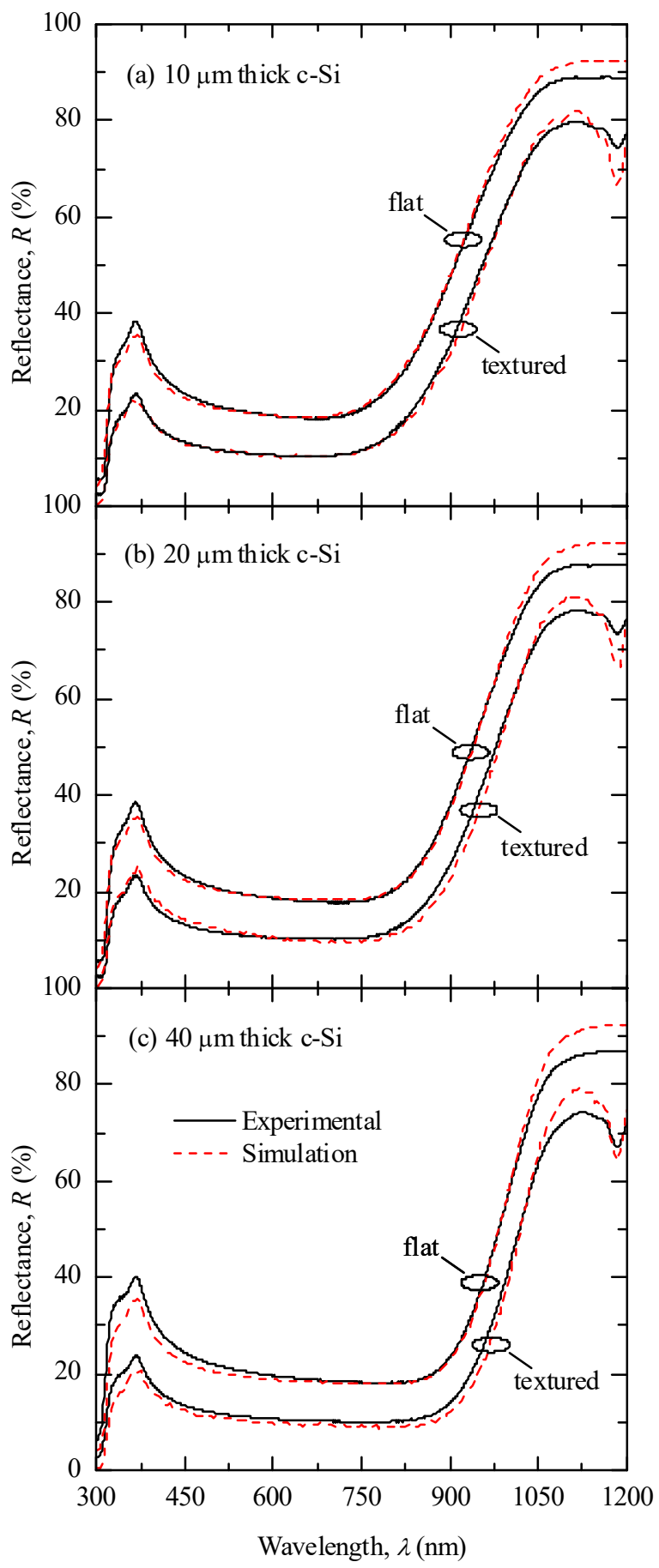

Fig. 3. Experimental and simulated reflectance data for the optical samples with three c-Si substrate thicknesses: (a) $10 \mu \mathrm{m}$, (b) $20 \mu \mathrm{m}$ and (c) $40 \mu \mathrm{m}$.

\section{Analysis of the origin of absorption improvement}

The excellent correspondence between experiments and optical calculations allows us to get a deeper insight into the optical benefits of the textured PDMS films when they are applied onto thin c-Si solar cells. Since we are interested in c$\mathrm{Si}$ solar cells for terrestrial applications, we consider an 
AM1.5g spectrum with $100 \mathrm{~mW} / \mathrm{cm}^{2}$ as our potential light source with a useful spectral range of 300 to $1200 \mathrm{~nm}$. Consequently, we can summarize the dependence of optical magnitudes (absorption, transmittance or reflectance) on wavelength by a potential photogenerated current density $\left(J_{\mathrm{ph}}\right)$. To do so, we must apply AM1.5g spectrum to the corresponding magnitude, integrate over wavelength range and translate the quantity of photons to $J_{\mathrm{ph}}$ considering that every photon generates only one electron-hole pair potentially collectable. In other words, with AM1.5g as photon flux in photons $/ \mathrm{cm}^{2} \cdot \mathrm{nm}$ :

$$
J_{p h}=q \cdot \int_{300}^{1200} X(\lambda) \cdot A M 1.5 g d \lambda
$$

where $q$ is the fundamental charge and $X$ is the reflectance $(R)$, transmittance $(T)$ or absorptance $(A)$ of the corresponding structure under analysis. For these calculations we consider that the $J_{\mathrm{ph}}$ value carried by AM1.5g in the mentioned wavelength range is $46.46 \mathrm{~mA} / \mathrm{cm}^{2}$.

To accurately simulate the potential gain in $J_{p h}$ for the finished solar cells, we introduce in the simulations the front surface structure used in such devices and shown in figure 2.(b). The main difference is the introduction of a silicon carbide (SiC) layer between the epoxy and the $\mathrm{Al}_{2} \mathrm{O}_{3}$ film. This combination has already been used in other solar cell structures fabricated by the group [25]. The optical parameters $n$ and $k$ of the $\mathrm{SiC}$ layers, which are similar to conventional silicon nitride films [26], are determined by spectroscopic ellipsometry measurements. Thicknesses of the layers of this stack are tuned to work as an optimum anti-reflection coating for AM1.5g, i. e. low reflection at wavelengths $\sim 600 \mathrm{~nm}$ where the photon flow is maximum.

The optical improvement due to the texturized PDMS films can be divided in three effects: (i) reduction of reflection at the air/glass interface; (ii) reduction of photons reflected at the $\mathrm{Al}_{2} \mathrm{O}_{3} / \mathrm{c}$-Si interface where the contrast between refractive indexes is maximum; and (iii) the improvement of light confinement properties once the photons are transmitted into the $\mathrm{c}-\mathrm{Si}$ absorber. In the following paragraphs the impact of texturized PDMS films on every mechanism is analysed.

Regarding photon reflection on the front surface, the textured surface helps in transmitting photons inside the material since the reflected photon can impinge again onto the PDMS surface of the opposite pyramid wall having a second opportunity to be transmitted. Through optical simulations we can calculate the light transmitted for both cases: a flat glass surface and a texturized PDMS. The former leads to a transmission of $96.0 \%$ which agrees with the difference in refractive indexes $\left(n_{\mathrm{air}}=1\right.$, $n_{\text {glass }}=1.5$ ) while the latter increases light transmission to about $\sim 99.8 \%$. The effect in the available $J_{\text {ph }}$ shows that transmitted photons are equivalent to $J_{\mathrm{ph}}=45.08 \mathrm{~mA} / \mathrm{cm}^{2}$ for the flat surface while with PDMS film we obtain $J_{\mathrm{ph}}=46.37 \mathrm{~mA} / \mathrm{cm}^{2}$, which means an increase of $1.29 \mathrm{~mA} / \mathrm{cm}^{2}$.

The second effect deals with photons reflected at $\mathrm{Al}_{2} \mathrm{O}_{3} / \mathrm{c}-\mathrm{Si}$ interface where the contrast of refractive index is maximum. In the optical simulator, we define a structure with the same front surface configuration, but with an infinitely thick c-Si absorber.
By doing so, we can calculate the photons that are transmitted into the c-Si for both cases: with and without the texturized PDMS film on top of the glass. The results are shown in figure 4. It should be mentioned that the transmission through the front $35 \mathrm{~nm}$ thick $\mathrm{Al}_{2} \mathrm{O}_{3}$ layer is almost identical to the light transmitted to c-Si and it has not been included in the graph. As it can be seen, for the flat surface a significant part of photons that are reflected at the $\mathrm{Al}_{2} \mathrm{O}_{3} / \mathrm{c}-\mathrm{Si}$ surface escape from the device increasing the total reflectance (in the graph indicated by the white area). On the other hand, the introduction of the texturized PDMS films scatters the light and part of the photons that are reflected at the $\mathrm{Al}_{2} \mathrm{O}_{3} / \mathrm{c}-\mathrm{Si}$ interface is internally reflected again preventing them to escape from the structure and reducing optical losses. Simultaneously, the absorption of every material can be also evaluated in these graphs. The most important parasitic absorption corresponds to the epoxy that shows a strong absorption in the UV part preventing most of the photons below $350 \mathrm{~nm}$ to reach the c-Si surface. Moreover, the introduction of PDMS film results in some absorption in the UV and IR part.

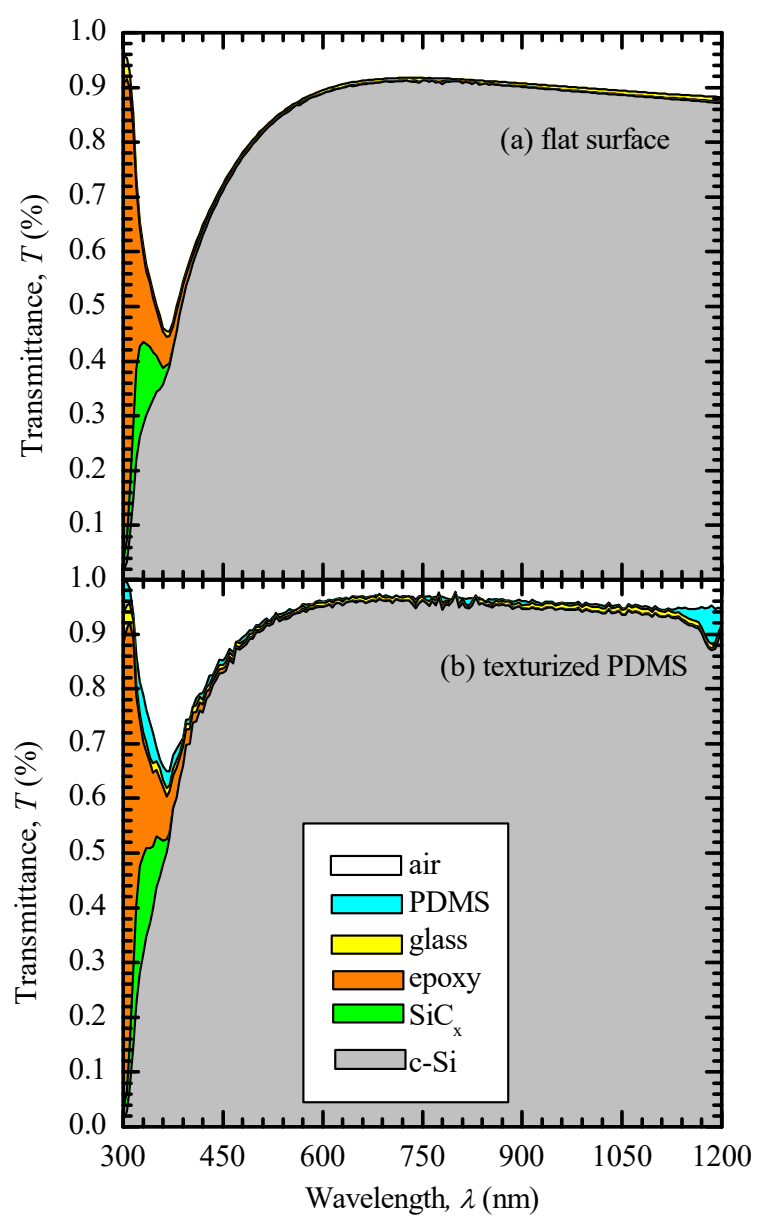

Fig. 4. Light transmitted through every layer following the front surface configuration of the experimental samples with (a) flat surface and (b) introducing PDMS foils. It should be mentioned that the $\mathrm{Al}_{2} \mathrm{O}_{3}$ film does not absorb any photon and its transmission data coincides with the one into c-Si.

Table I shows the corresponding $J_{p h}$ values at every layer. Despite $0.27 \mathrm{~mA} / \mathrm{cm}^{2}$ absorbed in the texturized PDMS film 
and a slight increase in parasitic absorption in the glass and the epoxy, the introduction of the texturized film improves the light transmitted to the c-Si leading to an increase in $J_{\mathrm{ph}}$ from 39.85 $\mathrm{mA} / \mathrm{cm}^{2}$ to $42.76 \mathrm{~mA} / \mathrm{cm}^{2}$, which means $2.91 \mathrm{~mA} / \mathrm{cm}^{2}$ more.

TABLE I

FRONT REFLECTANCE AND ABSORPTION IN EVERY LAYER EXPRESSED IN POTENTIAL PHOTOGENERATED CURRENT DENSITY

\begin{tabular}{lcc}
\hline \hline & Flat & Texturized PDMS \\
\hline Front reflection & $6.09 \mathrm{~mA} / \mathrm{cm}^{2}$ & $2.79 \mathrm{~mA} / \mathrm{cm}^{2}$ \\
PDMS & - & $0.27 \mathrm{~mA} / \mathrm{cm}^{2}$ \\
Glass & $0.26 \mathrm{~mA} / \mathrm{cm}^{2}$ & $0.32 \mathrm{~mA} / \mathrm{cm}^{2}$ \\
Epoxy & $0.20 \mathrm{~mA} / \mathrm{cm}^{2}$ & $0.25 \mathrm{~mA} / \mathrm{cm}^{2}$ \\
SiC & $0.06 \mathrm{~mA} / \mathrm{cm}^{2}$ & $0.07 \mathrm{~mA} / \mathrm{cm}^{2}$ \\
c-Si & $39.85 \mathrm{~mA} / \mathrm{cm}^{2}$ & $42.76 \mathrm{~mA} / \mathrm{cm}^{2}$ \\
\hline \hline
\end{tabular}

Finally, we focus on the light trapping properties inside c-Si absorber which is of crucial importance in such thin c-Si substrates. In figure 5,(a) we plot the internal absorptance of c$\mathrm{Si}$, i.e. absorbed photons relative to the photons that enter the cSi substrate, for the three substrate thicknesses explored in this work. In this case, we have defined an ideal back reflector at the rear surface in order to calculate the full potential of the light confinement properties. As it can be seen, c-Si internal absorption is improved at the IR spectrum in all cases when the texturized PDMS film is introduced confirming the enhanced light trapping properties. Notice that this magnitude neglects any reflection losses on the previous films, but depends on the range of angles of the incoming light and, therefore, on the light scattering introduced by the front texture. As a reference, we can calculate the internal absorption of the c-Si layer considering only vertical incidence of the light. With a perfect rear reflector, multiple reflections and Lambert-Beer law [23]:

$$
A(\lambda)=\frac{1-e^{-2 \alpha(\lambda) d}}{1-R_{\mathrm{int}} e^{-2 \alpha(\lambda) d}}
$$

where $\alpha(\lambda)$ is the absorption coefficient, $d$ is the physical thickness of the absorber and $R_{\text {int }}$ is the front internal reflectance calculated from the contrast of refractive indexes between c-Si and $\mathrm{Al}_{2} \mathrm{O}_{3}$. Due to the front texturization, light is scattered and can be trapped inside the absorber lengthening its optical path. Therefore, as a figure of merit, we can define a path length enhancement factor, $z(\lambda)$, to get the equivalent optical thickness, i.e. in equation (2) we should use $d \cdot z(\lambda)$ instead of just $d$. This $z(\lambda)$ factor will give us the information of the light confinement respect to the vertical incidence and flat surfaces. Then, isolating $z(\lambda)$ from equation (2):

$$
z(\lambda)=-\frac{1}{2 \cdot d \cdot \alpha(\lambda)} \ln \left(\frac{A-1}{A \cdot R_{\mathrm{int}}-1}\right)
$$

The results of applying equation (3) are shown in figure 5.(b) for the three explored thicknesses with texturized PDMS foils (for flat surfaces $z(\lambda)=1$ is obtained, not shown in the graph). As it can be seen, the optical length of the substrates is increased to almost a factor of 2 which is a significant improvement given the thin c-Si substrates.

To summarize the maximum improvement that could be expected in the fabricated solar cells fabricated with the structure proposed hereby, we calculate via simulations the potential $J_{\mathrm{ph}}$ with the front surface configuration of the solar cells and an ideal back reflector. The results are shown in Table II where a maximum increase in $J_{\mathrm{ph}}$ in the range of 3.44-3.90 $\mathrm{mA} / \mathrm{cm}^{2}$ is calculated.

TABLE II

SIMULATED PHOTOGENERATED CURRENT FOR SAMPLES WITH THE FRONT SURFACE CONFIGURATION AS THE SOLAR CELLS AND AN IDEAL BACK REFLECTOR.

\begin{tabular}{cccc}
\hline \hline & $10 \mu \mathrm{m}$ & $20 \mu \mathrm{m}$ & $40 \mu \mathrm{m}$ \\
\hline Flat & $27.50 \mathrm{~mA} / \mathrm{cm}^{2}$ & $30.13 \mathrm{~mA} / \mathrm{cm}^{2}$ & $32.03 \mathrm{~mA} / \mathrm{cm}^{2}$ \\
Texturized PDMS & $31.40 \mathrm{~mA} / \mathrm{cm}^{2}$ & $33.74 \mathrm{~mA} / \mathrm{cm}^{2}$ & $35.47 \mathrm{~mA} / \mathrm{cm}^{2}$ \\
Increment $\Delta S_{\mathrm{ph}}$ & $3.90 \mathrm{~mA} / \mathrm{cm}^{2}$ & $3.61 \mathrm{~mA} / \mathrm{cm}^{2}$ & $3.44 \mathrm{~mA} / \mathrm{cm}^{2}$ \\
Relative $\Delta S_{\mathrm{ph}}$ & $14.1 \%$ & $12.0 \%$ & $10.7 \%$ \\
\hline \hline
\end{tabular}

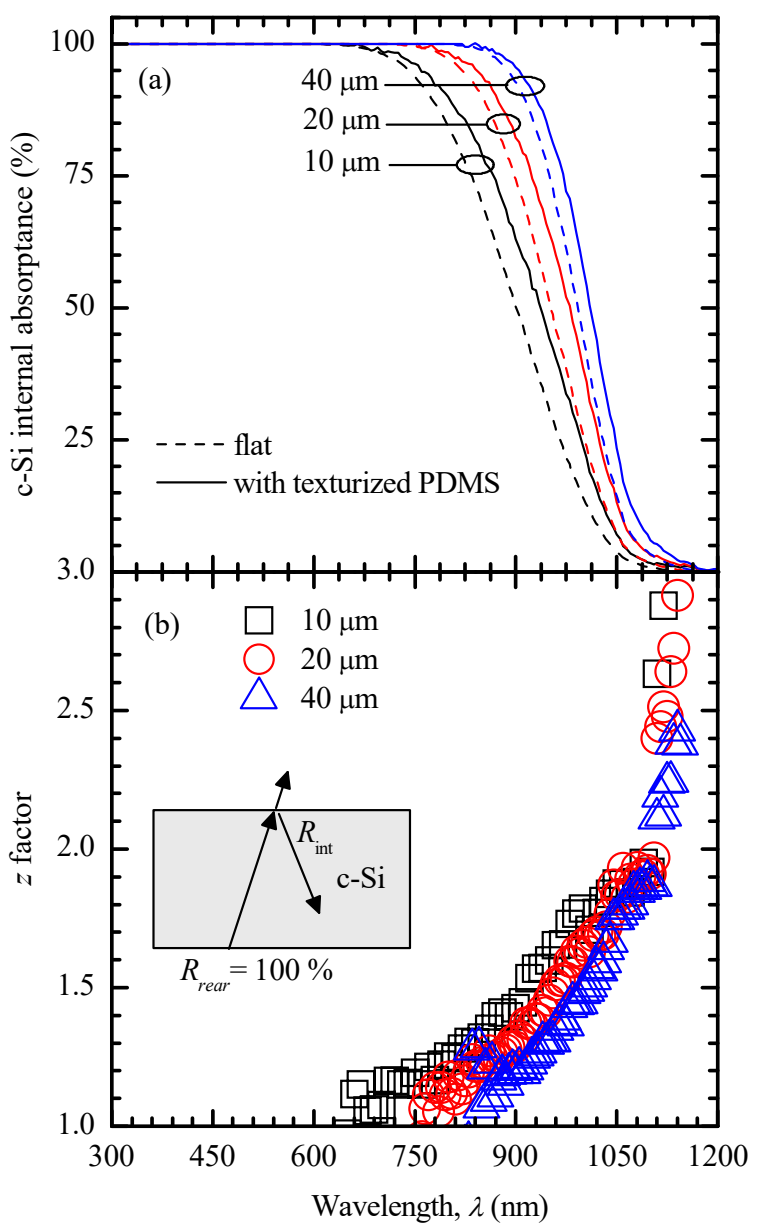

Fig. 5. (a) Simulated c-Si absorptance with respect to the transmitted photons inside the absorber for flat surfaces and with texturized PDMS film. A clear improvement in the IR spectrum is seen due to light confinement properties. (b) $z$ factor for the simulated structures with texturized PDMS foil.

\section{Experimental result on finished solar cells}

Finally, we have applied the texturized PDMS films onto finished IBC c-Si solar cells fabricated on $40 \mu \mathrm{m}$ thick substrates. The cross-section of the fabricated devices is shown in figure 2.(b). The applied technology is similar to the one reported by our research group in reference [27] where hole contacts are based on vanadium oxide $\left(\mathrm{VO}_{\mathrm{x}}\right)$ layers while 
electron contacts are defined by laser processing phosphorus doped silicon carbide film stack $\left(\operatorname{SiC}_{\mathrm{x}}(\mathrm{n})\right.$ stack). A detailed description of the fabrication process with the obtained results will be published elsewhere. Focusing on the work reported hereby, $1 \mathrm{x} 1 \mathrm{~cm}^{2}$ solar cells are measured under standard conditions (AM1.5g, $100 \mathrm{~mW} / \mathrm{cm}^{2}, 25{ }^{\circ} \mathrm{C}$ ) leading to an increase of short-circuit current density $\left(J_{s c}\right)$ from $26.7 \mathrm{~mA} / \mathrm{cm}^{2}$ to $28.4 \mathrm{~mA} / \mathrm{cm}^{2}$ when texturized PDMS films are placed on top of the glass. Despite the improvement of $1.7 \mathrm{~mA} / \mathrm{cm}^{2}$ in $J_{s c}$ is far from the maximum potential increase obtained from the simulations, it clearly demonstrates the benefits of the texturized PDMS films. It must be mentioned that the simulated $J_{p h}$ values are the maximum potential $J_{s c}$ that could be obtained in a final device without any recombination and ideal back reflector. Then, the suboptimal rear optical structure of the real device and the inherent recombination processes at the bulk and surfaces (in particular at the front) could perfectly explain the deviation from the ideal case.

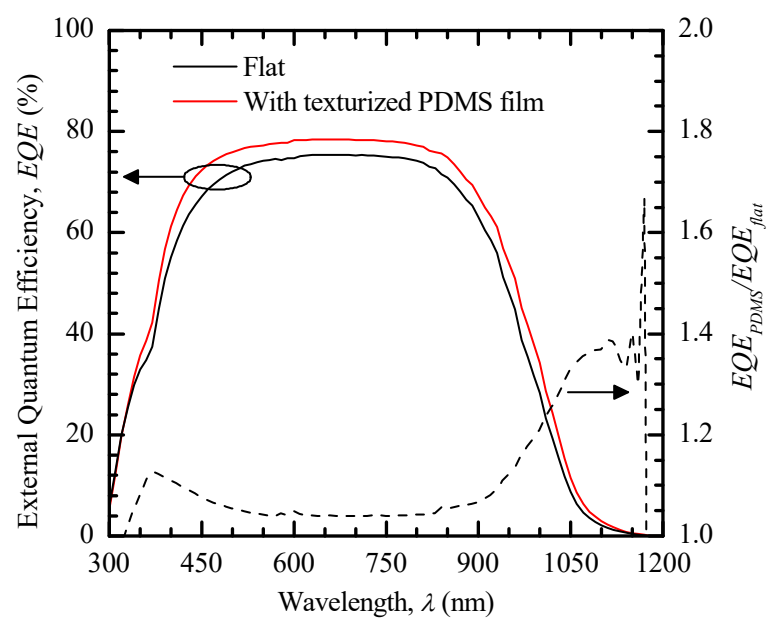

Fig. 6. External Quantum Efficiency measurements of $40 \mu \mathrm{m}$-thick finished solar cells with and without texturized PDMS. The ratio between these two magnitudes is also plotter on the left axis. A clear increase in EQE is observed when the texturized PDMS film is introduced, in particular at the IR part of the spectrum.

In order to get a deeper insight of the origin of this improvement, in figure 6 we show External Quantum Efficiency $(E Q E)$ of the best cell with $\left(E Q E_{P D M S}\right)$ and without $\left(E Q E_{f l a t}\right)$ texturized PDMS film. Additionally, the ratio between these two magnitudes is also plotted. As it can be seen, a plateau with a constant increase of 4-5\% is observed for wavelengths between $450-900 \mathrm{~nm}$. This improvement is well explained by the reduction of the front reflection due to the texturized surface, i.e. first two mechanisms in the previous subsection. In particular, a more significant improvement occurs in the 330$450 \mathrm{~nm}$ where for the flat device photons escape once they are reflected at the $\mathrm{Al}_{2} \mathrm{O}_{3} / \mathrm{c}-\mathrm{Si}$ interface, while the light scattering effect of the PDMS films reduces this loss. Interestingly, for very short wavelengths below $330 \mathrm{~nm}$ no EQE improvement is seen. This is explained by the absorption of the PDMS film (see figure 4). Finally, the most important improvement with factors up to 1.4 is observed at the IR part of the spectrum $(\lambda>900$ $\mathrm{nm})$. These photons are the ones that reach the rear surface and are internally reflected and, thus, the introduction of the textured PDMS films significantly improves light trapping properties of the thin c-Si solar cells. Based on these results, texturized PDMS films will be used on thinner devices whose fabrication will be addressed in the future.

\section{CONCLUSION}

This work reports on the replication of texturized surface by PDMS foils and its impact onto the light absorption of thin c-Si substrates. Firstly, we focused on obtaining a good replica of the master (random pyramid texturized c-Si surface). In particular, the effect of toluene dilution of PDMS was explored. Less defects and sharper pyramid vertexes are obtained with the 5:1 PDMS:toluene dilution which is the most diluted sample explored in this work. Once the texturized PDMS films were obtained, we applied them onto experimental samples that resemble solar cell structures based on 40,20 and $10 \mu \mathrm{m}$ thick c-Si substrates. A strong reduction of reflectance was experimentally measured which is related to an increase in c-Si absorptance. By ray tracing simulations, we can divide this optical improvement in three factors. Firstly, light is more efficiently transmitted into the device with $\sim 99.8 \%$ compared to $96.0 \%$ for flat surfaces. Secondly an increment of the transmitted light into c-Si absorber is demonstrated increasing $J_{\text {ph }}$ from 39.85 to $42.76 \mathrm{~mA} / \mathrm{cm}^{2}$. Finally, light scattered by the texturized PDMS film improves light trapping properties in the c-Si substrates leading to an increase of the optical length of the device by a factor of 2 . The combination of all these effects results in a potential $J_{\mathrm{ph}}$ increment of $3.44-3.90 \mathrm{~mA} / \mathrm{cm}^{2}$. The effect of these films has been measured on IBC $40 \mu$ m-thick solar cells with a significant increase in $J_{s c}$ of $1.7 \mathrm{~mA} / \mathrm{cm}^{2}$. From the analysis of EQE measurements, a clear improvement of the light trapping properties of these devices is observed.

\section{ACKNOWLEDGMENT}

The authors would like to thank Dr. E. Johnson from LPICM for his support in the spectroscopic ellipsometry measurements.

\section{REFERENCES}

[1] D.L. King and M.E. Buck, "Experimental optimization of an anisotropic etching process for random texturization of silicon solar cells", in Proc. of the $27^{\text {th }}$ IEEE Photovoltaic Specialist Conference, Las Vegas, USA, 1991, pp. 303-308.

[2] P. Campbell and M. A. Green, "Light trapping properties of pyramidally textured surfaces," J. Appl. Phys., vol. 62, pp. 243-249, 1987.

[3] Y.-T. Cheng, J.-J. Ho, S.-Y. Tsai, Z.-Z. Ye, W. Lee, D.-S. Hwang, S.-H. Chang, C.-C. Chang and K. L. Wang, "Efficiency improved by acid texturization for multi-crystalline silicon solar cells," Solar Energy, vol. 85, pp. 87-94, 2011.

[4] S.C. Baker-Finch, K.R. McIntosh and M. L. Terry, "Isotextured Silicon Solar Cell Analysis and Modeling 1: Optics", IEEE J. Photov., vol. 2, pp. 457-464, 2012.

[5] H. Sai, H. Jia, and M. Kondo, "Impact of front and rear texture of thin-film microcrystalline silicon solar cells on their light trapping properties, $J$. Appl. Phys., vol. 108, pp. 044505, 2010.

[6] S. Fäy, U. Kroll, C. Bucher, E. Vallat-Sauvian, and A. Shah, "Low pressure chemical vapour deposition of $\mathrm{ZnO}$ layers for thin-film solar cells: temperature-induced morphological changes", Sol. Energy Mater. Sol. Cells., vol. 86, pp. 385-397, 2005.

[7] X. Liu, P.R. Coxon, M. Peters, B. Hoex, J.M. Cole and D.J. Fray, "Black 
silicon: fabrication methods, properties and solar energy applications", Energy Environ. Sci., vol. 7, pp. 3223-3263, 2014.

[8] P. Ortega, E. Calle, G. von Gastrow, P. Repo, D. Carrió, H. Savin, R. Alcubilla, "High-efficiency black silicon interdigitated back contacted solar cells on p-type and n-type c-Si substrates", Prog. Photovolt.: Res. Appl., vol. 23, pp. 1448-1457, 2015.

[9] C.H. Hsu, S.T. Connor, M.X. Tang and Y. Cui, "Wafer-scale silicon nanopillars and nanocones by Langmuir-Blodgett assembly and etching", Appl. Phys. Lett., vol. 93, pp. 133109, 2008.

[10] M. Jost, E. Köhnen, A.B. Morales-Vilches, B. Lipovsek, K. Jäger, B. Macco, A. Al-Ashouri, J. Krc, L. Korte, B. Rech, R. Schlatmann, M. Topic, B. Stannowski and S. Albrecht, "Textured interfaces in monolithic perovskite/silicon tandem solar cells: advanced light management for improved efficiency and energy yield", Energy Environ. Sci., vol. 11, pp. 3511-3523, 2018.

[11] C.T. Trinh, N. preissler, P. Sonntag, M- Muske, K. Jäger, M. Trahms, R. Schlatmann, B. Rech and D. Amkreutz, "Potential of interdigitated backcontact silicon heterojunction solar cells for liquid phase crystallized silicon on glass with efficiency above 14\%", Sol. Energy Mat. Sol. Cells, vol. 174, pp. 187-195, 2018.

[12] C. Ulbrich, A. Gerber, K. Hermans, A. Lambertz and U. Rau, "Analysis of short circuit current gains by an anti-reflective textured cover on silicon thin film solar cells", Progr. Photovolt.: Res. Appl., vol. 21, pp. 16721681, 2013.

[13] L. Sainiemi, V. Jokinen, A. Shah, M. Shpak, S. Aura, P. Suvanto and S. Franssila, "Non-Reflecting Silicon and Polymer Surfaces by Plasma Etching and Replication”, Adv. Mater., vol. 23, pp. 122-126, 2011.

[14] S. Manzoor, Z.J. Yu, A. Ali, W. Ali, K.A. Bush, A.F. Palmstrom, S.F. Bent, M.D. McGehee and Z.C. Holman, "Improved light management in planar silicon and perovskite solar cells using PDMS scattering layer", Sol. Energy Mat. Sol. Cells, vol. 173, pp. 59-65, 2017.

[15] H. Sai, H. Umishio, T. Matsui, S. Nunomura, T. Kawatsu, H. Takato and K. Matsubara, "Impact of silicon wafer thickness on photovoltaic performance of crystalline silicon heterojunction solar cells", Jpn. J. Appl. Phys., vol. 57, 08RB10, 2018.

[16] M.L. Addonizio, A. Antonaia, L. Fusco, "Plasma etched c-Si wafer with proper pyramid-like nanostructures for photovoltaic applications", Appl. Surf. Sci., vol. 467-468, pp. 143-150, 2019.

[17] H. Savin, P. Repo, G. von Gastrow, P. Ortega, E. Calle, M. Garín, R. Alcubilla, "Black silicon solar cells with interdigitated back-contacts achieve 22.1\% efficiency", Nat. Nanotechnol., vol. 10, pp. 624-628, 2015.

[18] G. López, P.R. Ortega, C. Voz, I. Martín, M. Colina, A.B. Morales, A. Orpella and R. Alcubilla, "Surface passivation and optical characterization of $\mathrm{Al}_{2} \mathrm{O}_{3} / \mathrm{a}-\mathrm{SiC}_{\mathrm{x}}$ stacks on c-Si substrates", Belstein J. Nanotechnol., vol. 4, pp. 726-731, 2013.

[19] B. Hoex, S. B. S. Heil, E. Langereis, M. C. M. van de Sanden and W. M. M. Kessels, "Ultralow surface recombination of c-Si substrates passivated by plasma-assisted atomic layer deposited $\mathrm{Al}_{2} \mathrm{O}_{3}$ ", Appl. Phys. Lett., vol. 89, pp. 042112, 2006

[20] R. Santbergen, T. Meguro, T. Suezaki, G. Koizumi, K. Yamamoto, M. Zeman, "GenPro4 optical model for solar cell simulation and its application to multijunction solar cells", IEEE J. Photov., vol. 7, pp. 919926, 2017.

[21] E. Palik Ed., "Handbook of Optical Constants of Solids", San Diego, CA, USA: Academic Press Inc., 1998, pp. 395

[22] M.A. Green and M.J. Keevers, ”Optical Properties of Intrinsic Silicon at 300 K", Prog. Photovolt.: Res. Appl., vol. 3, pp.189-192, 1995.

[23] D. Swinehart, "The beer-lambert law," J. Chem. Educ., vol. 39, pp. 333$335,1962$.

[24] https://www2.pvlighthouse.com.au/resources/photovoltaic\%20materials/ refractive $\% 20$ index/refractive $\% 20$ index.aspx

[25] P. Ortega, G. López, D. Muñoz, I. Martín, C. Voz, C. Molpeceres, R. Alcubilla, "Fully low temperature interdigitated back-contacted c-Si(n) solar cells based on laser-doping from dielectric stacks", Sol. Energy Mat. Sol. Cells, vol.169, pp. 107-112, 2017.

[26] G. López, P. Ortega, C. Voz, I. Martín, M. Colina, A.B. Morales, A. Orpella, R. Alcubilla, "Surface passivation and optical characterization of $\mathrm{Al}_{2} \mathrm{O}_{3} / \mathrm{a}-\mathrm{SiC}_{\mathrm{x}}$ stacks on c-Si substrates", Belstein J. Nanotechnol., Vol. 4, pp. 726-731, 2013.

[27] G. Masmitjà, L.G. Gerling, P. Ortega, J. Puigdollers, I. Martín, C. Voz and R. Alcubilla, " $\mathrm{V}_{2} \mathrm{O}_{\mathrm{x}}$-based hole-selective contacts for c-Si interdigitated 